\title{
EVALUATION AND VALIDATION OF STABILITY INDICATING RP-HPLC METHOD FOR THE USE OF BERBERINE FROM COPTIS TEETA BARK AS ANTI-CANCER PHYTOCHEMICAL
}

\author{
MADHURI CHONDHE*, SWAPNALI HANDE, SONIA SINGH \\ Department of Pharmaceutical Sciences, Alard College of Pharmacy, Marunje, Hinjewadi, Pune, Maharashtra, India. \\ Email: poohande46@gmail.com
}

Received: 29 November 2020, Revised and Accepted: 18 February 2021

\section{ABSTRACT}

Objective: A new method of analysis using high-performance liquid reverse chromatography (HPLC) to calculate berberine in Coptis teeta bark was created in addition to the validation research.

Methods: Berberine was analyzed with potassium hydrogen phosphate and acetonitrile using the SunFire C18 column at a flow rate of $1.0 \mathrm{ml} / \mathrm{min}$; $5 \mu(4.6 \times 250 \mathrm{~mm})$ was detected at $347 \mathrm{~nm}$.

Results: For precision, selectivity, and linearity, the technique was tested. The quantification of berberine did not conflict with the existence of other chemical components. Between concentrations of 60 and $180 \mathrm{ppm}$, the calibration curve was linear. The precision ranged from $9.0 \%$ to $102.0 \%$ and $2 \%$ was the relative standard deviation.

Conclusion: Finally, this method of HPLC enhancement is simple, effective and has been used to classify and quantify berberine successfully. This can be useful for the study of different berberine-containing plant extracts and can also be used to measure berberine from formulation to herbal formulation.

Keywords: HPLC, Berberine, Coptis teeta, Validation.

(C) 2021 The Authors. Published by Innovare Academic Sciences Pvt Ltd. This is an open access article under the CC BY license (http://creativecommons.org/ licenses/by/4.0/) DOI: http://dx.doi.org/10.22159/ajpcr.2021v14i4.40400. Journal homepage: https://innovareacademics.in/journals/index.php/ajpcr

\section{INTRODUCTION}

In industrialized societies, about $31.4 \%$ of the population, $42-69 \%$ in the United States, $71 \%$ of Canadians and $90 \%$ of the British population consume dietary supplements or natural health products (Vitamins, minerals, amino acids, essential fatty acids, herbal products, traditional Chinese medicines, homeopathic medicines, and probiotics) for treatment, including disposal in urbanized and resource-poor countries, where pretenders sell impure or mixed herbal medicines, where pretenders sell impure or mixed herbal medicines [1,2]. The safety, quality, and efficacy of herbal products is an equally important public health concern. It is possible that the initiation of systematic validation would manage the production of herbal products and medicinal products of mixed or deprived quality, and ultimately ensure their rational use [3]. For quality evaluation and standardization of polyherbal formulations, physicochemical parameters, biochemical analysis, microbiological features, HPLC, and HPTLC fingerprint profiles may be used as marker parameters. HPLC is a fast and accurate technique for individual compound quantification [4].

The "goddess of all healings" is called Ayurveda and is one of the most efficient traditional systems of medicine with many medicinal and healing properties. Individual herbs are not sufficient to achieve the desired therapeutic effect, according to Ayurveda. It offers a stronger therapeutic effect with reduced toxicity when partially configured as a multi-plant composition [1]. Approximately $31.4 \%$ of the population in industrial societies, $42-69 \%$ in the United States, $71 \%$ in Canada, and $90 \%$ in the United Kingdom consume dietary supplements or natural health products (Vitamins, minerals, amino acids, essential fatty acids, herbal products, traditional Chinese food medicines, homeopathic medicines, and probiotics) for therapeutic purposes. In developed nations, where fake herbal medicines are marketed and in countries without money, the quality of herbal products is a major public health issue. The implementation of scientific verification should regulate the production of, and eventually ensure the fair use of, low-quality herbal or herbal products [3]. As parameter markers for quality evaluation and standardization of pilocarpine formulations, physicochemical parameters, biochemical analysis, microbiological properties, HPLC, and HPTLC fingerprint profiles can be used. HPLC is a rapid and precise process for the quantification of individual compounds [4].

Coptis teeta Wall is a perennial plant belonging to the family Ranunculaceae. It is rich in alkaloids such as lignans, phenylpropanoids, flavonoids, phenolic acids, carbohydrates, and steroids such as berberine, palmatine, jatrorrhizine, coptisine, columbamine and epiberine, and several secondary metabolites $[5,6]$. Over the past decade, extensive research has shown that berberine has a wide range of pharmacological activities, including antimicrobial and antibacterial activity, diarrhea, antihypertensive activity, rhythmic activity, antihypertensive activity, anti-inflammatory activity, antihypertensive activity, depressive activity, antioxidant activity, and antidiabetic activity $[7,8]$.

In this study, our objective is to use RP-HPLC-UV-DAD to differentiate, identify and measure the single natural anticancer drugs, i.e., berberine in Coptis teeta plant extract. Furthermore, validated was the HPLC-DAD process for measuring these drugs. The validation of chromatographic recognition of berberine may contribute to the process of equivalence between herbal extracts and polyherbal formulation and drug expansion.

\section{METHODS}

\section{Chemicals}

HPLC-grade solvents such as acetonitrile, methanol, orthophosphoric acid, and water were obtained from Merck Ltd. Bangalore India. Standards from Natural Remedies Ltd. Bangalore India were purchased (Table 1).

\section{Plant material}

The Coptis teeta fresh bark was acquired from the local market, Pune District, Maharashtra State, India. Department of Pharmacognosy 
Alard College of Pharmacy Pune confirmed their identity and authentication by correlating their morphological and microscopic characters with those given in literature. In the shade, the fresh bark was dried, finely powdered, and the powder was passed through 80 mesh sieves and deposited at room temperature $\left(30 \pm 2^{\circ} \mathrm{C}\right)$ in airtight containers.

\section{Extract preparation}

The powdered root was processed for $72 \mathrm{~h}$ at $80^{\circ} \mathrm{C}$ with a water-alcohol mixture (1:1). The extract was collected, filtered and vacuum dried with a rotary vacuum evaporator after full extraction (Buchi). The extract has been stored for further use in an airtight glass bottle. Validation of the alcoholic extract method was carried out.

\section{Preparation of standard solution}

Berberine $10 \mathrm{mg}$ was precisely weighed and transferred into a volumetric flask of $25 \mathrm{~mL} .20 \mathrm{~mL}$ of diluent was added and sonicated for $15 \mathrm{~min}$ in an ultrasonic water bath. The solution was cooled and diluent volume was produced up to the mark.

\section{Preparation of test solution}

Approximately $20 \mathrm{mg}$ of plant extract was consumed in a $100 \mathrm{~mL}$ volumetric flask. $70 \mathrm{~mL}$ of diluent was added and then echoed for $20 \mathrm{~min}$ in an ultrasonic water bath. The solution was cooled and diluent volume was produced. It was then filtered with a $0.45 \mu$ syringe filter. The test solution was used as the resulting solution.

\section{Chromatographic conditions for HPLC}

A Waters 2695 Alliance system with a 2996 photodiode array detector (PDA) and 2489 UV/Visible detector was used to conduct HPLC (UV). On a reverse-phase, $250 \times 4.6 \mathrm{~mm}, 5-\mu \mathrm{m}$, Sunfire C18 column, the standard was resolved as Berberine. A mobile phase of 50 millimoles of potassium di-hydrogen phosphate in water was prepared and $\mathrm{pH}$ 2.5 was modified with diluted OPA (solvent-A) and acetonitrile (100\%) (Solvent-B). The applied gradient software is defined in Table 2. The flow rate of the mobile phase was held at $1 \mathrm{ml} / \mathrm{min}$. The column was inundated for $30 \mathrm{~min}$ through the preliminary mobile process prior to the first injection. The column temperature has been held at $30^{\circ} \mathrm{C}$. The volume of the injection was determined to remain at $10 \mu \mathrm{L}$. By optimizing wavelength, the PDA was set to provide the best response for two peaks at $347 \mathrm{~nm}$ to obtain the chromatogram. By comparing the retention time and spectrum obtained from the sample and standard solutions, the standard Berberine was established. The current attempt was made in an air-conditioned room maintained at a temperature of $25^{\circ} \mathrm{C}[9-11]$

\section{Preparation of calibration graph}

From $50 \%$ to $150 \%$ of the working concentration level for Berberine, the linearity of peak area response for Berberine was identified. Seven different known concentrations of the stock solution of Berberine were diluted. The concentration map (as X-value) against the region (as Y-value) was planned.

\section{VALIDATION OF HPLC METHOD}

In terms of specificity, precision, accuracy, and robustness, the projected HPLC technique was validated as per the guidelines of the International Conference on Harmonization (ICH) [12-15].

\section{Specificity}

The specificity of the technique was analyzed by estimating the peak purity of berberine using the Waters empower software program and diode array detector moreover shows of purity angle, purity threshold, and purity flag.

Table 1: Standard used for validation studies

\begin{tabular}{llll}
\hline S. No. & Name of standard & Batch No & Potency (\%) \\
\hline 1. & Berberine & T12H035 & 93.80
\end{tabular}

\section{Precision}

Precision was analyzed in terms of device precision, precision of the procedure, and intermediate precision.

\section{System precision}

System precision was performed by six repeat injections from the same standard vial and was expressed in terms of tailing, plate count, and resolution percent relative standard deviation (percent RSD).

\section{Method precision}

The sample was examined six times by the aforementioned system. In terms of percent RSD, the percent assay for Berberine was articulated.

\section{Intermediate precision}

Intermediate precision was performed by various analysts on various systems, one with a 2996 PDA Waters e2695 Alliance system and the other with a 2489 ultraviolet (UV) detector by scrutinizing six distinct extract samples and was recorded in terms of percent RSD.

\section{Recovery studies}

From recovery research, the accuracy of the procedure was determined by adding an identified quantity of standard to the pre-analyzed sample at the $80 \%, 100 \%$, and $120 \%$ stage, accompanied by a duplicate quantitative study of the proposed technique.

\section{Robustness}

The technique's robustness was determined by a slight divergence in the parameters of the system. Variations in column chemistry, wavelength, column temperature, flow rate, and mobile phase gradient were the parameters selected. The retention time of berberine was determined and a percentage of RSD was observed using parameters of device suitability.

To verify the content of berberine according to the method defined under chromatographic conditions by HPLC, herbal extract was analyzed. All inquiries were replicated three times, with implications expressed in mean $\pm \mathrm{SD}$.

\section{RESULTS AND DISCUSSION}

In the HPLC technique, the mobile phase ratio was optimized by measuring various solvent compositions of unreliable polarity, column chemistry, column temperature, and mobile phase $\mathrm{pH}$, and the finest fallout was obtained using the current technique, which produces highly proportionate peaks with good resolution between each standard and other peaks (Fig. 1). In addition, at this wavelength analyte, the scanning wavelength selected was $226 \mathrm{~nm}$ to provide similar performance, showing optimal response. With a holding time of $11.4 \mathrm{~min}$, Berberine was acceptably resolved.

The calibration graph showed a working concentration level of $50-150 \%$ for berberine with appropriate correlation coefficients of 0.9990 and 0.9992 for berberine $(59-184 \mu \mathrm{g} / \mathrm{mL}$ ) (Table 3). Fig. 2 shows the graph for each standard.

In system precision, method precision, and intermediate precision values are defined against sample application and peak area scanning and are expressed in terms of percent RSD. Percent RSD values were found to be $1.06 \%$ for Berberine for machine precision. The precision

Table 2: Details of Gradient program

\begin{tabular}{llll}
\hline Time (min) & Flow (mL/min) & \% solvent A & \% solvent B \\
\hline 0 & 1.0 & 80 & 20 \\
25 & 1.0 & 40 & 60 \\
30 & 1.0 & 50 & 50 \\
35 & 1.0 & 50 & 50 \\
40 & 1.0 & 80 & 20 \\
45 & 1.0 & 80 & 20 \\
\hline
\end{tabular}




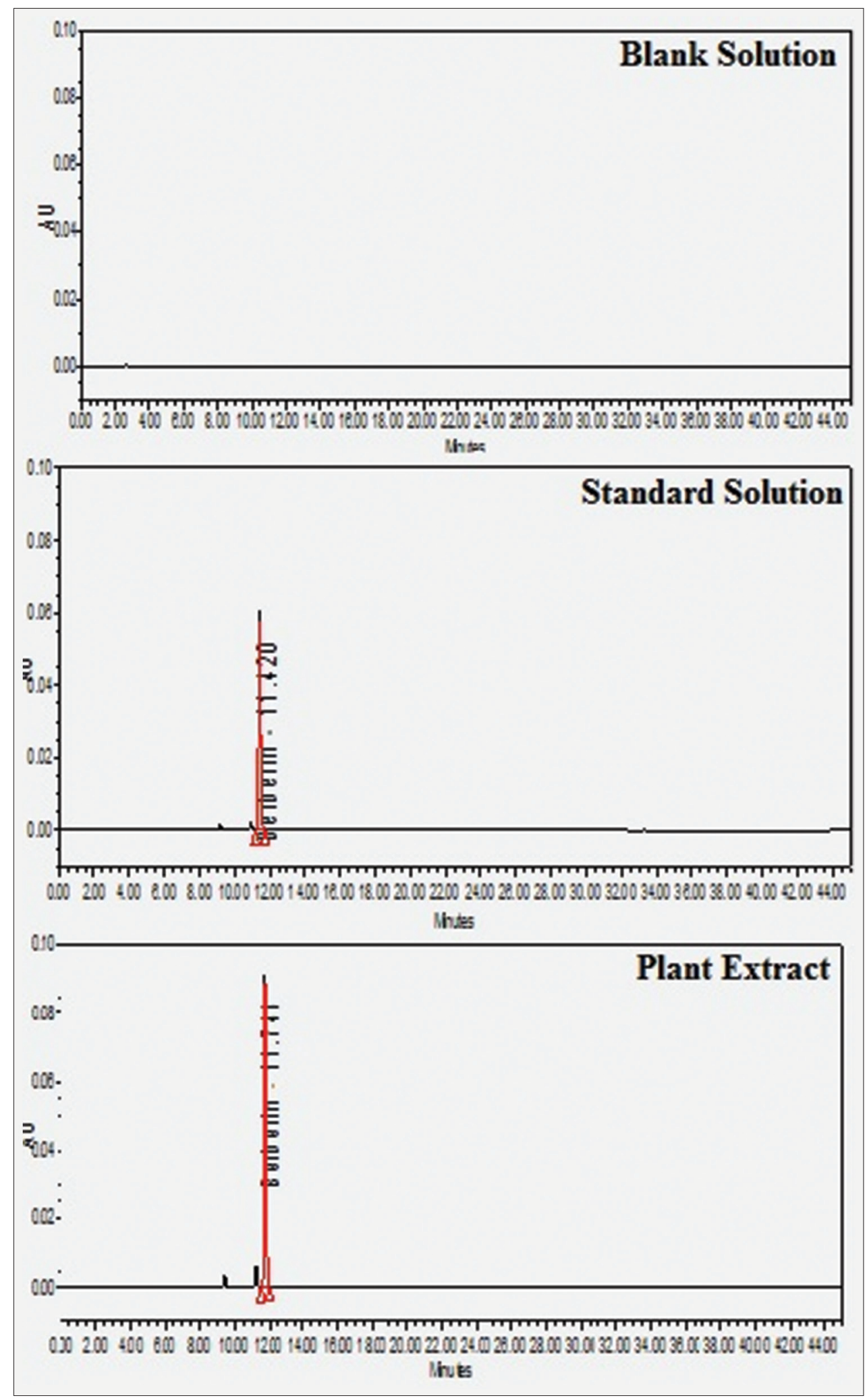

Fig. 1: Chromatograms for blank, standard, and sample

of the method was achieved and the percent RSD value for Berberine was found to be $1.02 \%$. Percent RSD values among the two analysts for intermediate precision were found to be $1.39 \%$ for Berberine. The percent RSD values for the values of system precision, method precision, and intermediate precision showed that the proposed methodology offers a reasonable degree of system precision, method precision, and intermediate precision.
Comparing their respective spectra at peak start, peak apex, and peak end positions of the spot from standard and extracts, the peak purity of each analyte was evaluated. In Table 4, the purity angle and purity threshold values are given.

Via robustness, the method given was optimized. For each parameter, the peak area for each analyte was determined and less than $2 \%$ percent 
Table 3: Linearity of berberine

\begin{tabular}{lll}
\hline \% Level & $\begin{array}{l}\text { Conc. of } \\
\text { berberine } \mathbf{( p p m )}\end{array}$ & $\begin{array}{l}\text { Average peak } \\
\text { area of berberine }\end{array}$ \\
\hline 50 & 59.4 & 207133 \\
60 & 75.6 & 264344 \\
70 & 97.2 & 346647 \\
100 & 118.8 & 426788 \\
120 & 140.4 & 494727 \\
140 & 162.0 & 585161 \\
150 & 183.6 & 659179 \\
$\mathrm{R}^{2}$ & 0.9994 & \\
Slope of Regression line & 3645 & \\
y-intercept & 9649 & \\
\hline
\end{tabular}

Table 4: Specificity of berberine

\begin{tabular}{lllll}
\hline Sr. No. & Sample name & $\begin{array}{l}\text { Analyte } \\
\text { name }\end{array}$ & $\begin{array}{l}\text { Purity } \\
\text { flag }\end{array}$ & Specificity \\
\hline 1. & Coptis teeta Extract & Berberin & No & Specific \\
2. & Standard & Berberin & No & Specific \\
3. & Blank & No Peak & - & - \\
\hline
\end{tabular}

Table 5: Robustness for berberine

\begin{tabular}{llllll}
\hline $\begin{array}{l}\text { Robustness } \\
\text { parameter }\end{array}$ & & $\begin{array}{l}\text { \% } \\
\text { RSD }\end{array}$ & $\begin{array}{l}\text { Peak } \\
\text { tailing }\end{array}$ & $\begin{array}{l}\text { Theoretical } \\
\text { plates }\end{array}$ & Remark \\
\hline Wavelength & 342 & 0.55 & 1.134 & 44410 & Pass \\
$(\mathrm{nm})$ & 347 & 0.67 & 1.120 & 44646 & Pass \\
& 352 & 0.54 & 1.134 & 44411 & Pass \\
Temperature & 20 & 0.57 & 1.15 & 43364 & Pass \\
$\left({ }^{\circ} \mathrm{C}\right)$ & 25 & 0.67 & 1.12 & 44646 & Pass \\
& 30 & 0.39 & 1.11 & 41507 & Pass \\
Flow & 0.9 & 1.66 & 1.058 & 49428 & Pass \\
$(\mathrm{mL} / \mathrm{min})$ & 1.0 & 0.67 & 1.116 & 44645 & Pass \\
& 1.1 & 0.32 & 1.122 & 39620 & Pass \\
\hline
\end{tabular}

Table 6: Recovery for berberine

\begin{tabular}{llll}
\hline Analyte & Recovery level & \% Recovery & Average \% recovery \\
\hline Berberine & $80 \%-1$ & 100.64 & 100.28 \\
& $80 \%-2$ & 104.78 & \\
& $80 \%-3$ & 95.41 & \\
& $100 \%-1$ & 96.15 & 103.40 \\
& $100 \%-2$ & 107.42 & \\
$100 \%-3$ & 106.63 & \\
& $120 \%-1$ & 102.76 & 101.06 \\
& $120 \%-2$ & 102.31 & \\
$120 \%-3$ & 98.12 & \\
\hline
\end{tabular}

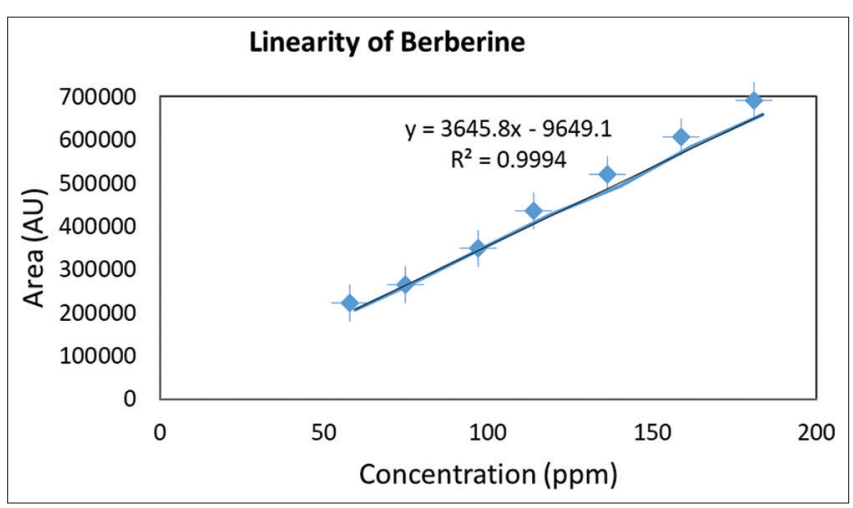

Fig. 2: Linearity graphs for standard of RSD was found. The percent RSD values as shown in Table 5 indicate improved method robustness.

The recovery analysis was performed at $80 \%, 100 \%$, and $120 \%$ of working concentration by spiking accepted amounts of standards into placebo solution. The overall percentage of recovery was found to be $101 \%$ for Berberine (Table 6).

\section{CONCLUSION}

The current investigation culminated in the development of a Berberine RP-HPLC-UV-DAD analysis method that was validated in terms of linearity, consistency, precision, specificity, suitability, and robustness of the device. In addition to its novelty for the determination of berberine at single wavelength, the presented method is sufficiently fast, simple, and sensitive as well as accurate and precise in accordance with ICH guidelines. The assay of the active ingredients did not interact with the excipients in the other plant chemicals. For routine analysis of berberine, the proposed analytical method is therefore recommended, either as such or in different dosage types. Moreover, in many developing countries or field stations, where specialized analytical equipment is not usable, the approach can be applied.

\section{ACKNOWLEDGMENTS}

The authors are grateful for the financial support provided by Alard College of Pharmacy, Marunje, Hinjewadi, Pune, India.

\section{AUTHORS' CONTRIBUTION}

The involvement of Dr. Madhuri Chondhe and Miss Swapnali Hande included the selection of samples, the design and performance of laboratory work, the interpretation of findings, and the preparation of the report. Contributions included data analysis and identification of the compounds by Dr. Madhuri Chondhe, Miss Swapnali Hande and Dr. Sonia Singh. Each author interpreted and permitted the submission of the last manuscript.

\section{CONFLICTS OF INTEREST}

No conflicts of interest are declared by the authors

\section{AUTHORS FUNDING}

None.

\section{REFERENCES}

1. Dev SK, Choudhury PK, Srivastava R, Sharma M. Antimicrobial, antiinflammatory and wound healing activity of polyherbal formulation. Biomed Pharmacother 2019;111:555-67.

2. Mandal M, Misra D, Ghosh NN, Mandal V. Physicochemical and elemental studies of Hydrocotyle javanica Thunb. For standardization as herbal drug. Asian Pac J Trop Biomed 2017;7:979-86.

3. Hazra AK, Chakraborty B, Mitra A, Sur TK. A rapid HPTLC method to estimate piperine in Ayurvedic formulations. J Ayurveda Integr Med 2019;10:284-54

4. Abraham A, Samuel S, Mathew L. Phytochemical analysis of Pathyashadangam kwath and its standardization by HPLC and HPTLC. J Ayurveda Integr Med 2020;11:153-8.

5. Bajpay A, Nainwal RC, Singh D. Coptis teeta: A potential endemic and endangered medicinal plant of Eastern Himalayas. J Pharmacogn Phytochem 2019;8:245-8.

6. Payum T. Distribution, ethnobotany, pharmacognosy and phytoconstituents of Coptis teeta wall.: A highly valued and threatened medicinal plant of Eastern Himalayas. Pharmacogn J 2017;9:s28-34.

7. Goswami AK, Gogoi N, Shakya A, Sharma HK. Development and validation of high-performance thin-layer chromatographic method for quantification of berberine in rhizomes of Coptis teeta Wall, an endangered species collected from Arunachal Pradesh, India. J Chromatogr Sci 2019;57:411-7.

8. Latif A, Razique A, Asadullah RS, Zuberi RH. Phytochemical and physico-chemical study of Coptis teeta Wall.: An effective drug of 
choice in ocular ailments. Eur J Integr Med 2008;1:22-3.

9. Kongkiatpaiboon S, Duangdee N, Prateeptongkum S, Tayana N, Inthakusol W. Simultaneous HPLC analysis of crebanine, dicentrine, stephanine and tetrahydropalmatine in Stephania venosa. Rev Bra Farmacogn 2017;27:691-7.

10. González-González RM, Barragán-Mendoza L, Peraza-Campos AL, Muñiz-Valencia R, Ceballos-Magaña SG, Parra-Delgado H. Validation of an HPLC-DAD method for the determination of plant phenolics. Rev Bras Farmacogn 2019;29:689-93

11. Alquadeib BT. Development and validation of a new HPLC analytical method for the determination of diclofenac in tablets. Saudi Pharm J 2019;27:66-70.

12. International Conference on Harmonization. International Conference on Harmonization of Technical Requirements for the Registration of Pharmaceuticals for Human Use 1996: Q2B. Guideline on Validation of Analytical Procedure-Methodology. London: International Conference on Harmonization; 1996.

13. Battu PR, Reddy MS. Development and validation of RP-HPLC for the rabeprazole sodium in pharmaceutical formulations and human plasma. Asian J Res Chem 2009;2:49-51.

14. Gnoatto SC, Schenkel EP, Bassani VL. HPLC method to assay total saponins in Ilex paraguariensis aqueous extract. J Braz Chem Soc 2005; 16:723-5.

15. Reddy B, Reddy YR. Validation and stability indicating RP-HPLC method for the determination of sildenafil citrate in pharmaceutical formulations and human plasma. J Chem 2008;5:1117-22. 